\title{
A Decision Support System Based on RCM Approach to Define Maintenance Strategies
}

\author{
Thárcylla Clemente, Adiel Almeida-Filho, Marcelo Alencar, \\ and Cristiano Cavalcante \\ Federal University of Pernambuco, Production Engineering Departament, \\ Post Box 7471, 50630971, Recife, Brazil \\ thnegreiros@ymail.com, atalmeidafilho@yahoo.com.br, \\ \{marcelohazin, cristianogesm\}@gmail.com
}

\begin{abstract}
This article presents a Decision Support System which focuses on an important organizational context: maintenance decisions. Usually, a specific management system is required to deal with data on failure, reliability, maintainability and availability regarding equipment. The maintenance context is surrounded by uncertainty and does not provide a clear profit from its activities, and thus requires a tool which fits in with organizational needs. The tool presented in this paper considers the requirements and approaches of an industrial production system, using concepts and methodologies from Reliability Centered Maintenance (RCM) to establish maintenance strategies, such as inspection and preventive maintenance planning, and also takes into consideration sophisticated MCDA and FMECA models for strategic decision making.
\end{abstract}

Keywords: Decision Support System, Reliability Centered Maintenance, Maintenance Strategies.

\section{Introduction}

The globalized context requires organizations to formulate a strategic plan to ensure their permanency in the competitive market. Despite the heavy investments that many organizations have been making in communications, operations and negotiations, competitiveness requires organizations to maintain a continuous and updated flow of information within the environment of their organization in order to ensure their survival and to position themselves vis-à-vis constant change [1]. Thus, companies are constantly seeking to improve their performance [2].

Improving performance is linked to both the production function and the business function. Both are associated with the strategic objective of the organization. The activities performed in an organization all contribute to maintenance management, since all activities are related to maintaining the reliability of the operational system at a high level by replacing equipment or parts or maintaining operational conditions [3].

To fulfill its strategic objectives, an organization needs to adopt a management plan that is able to integrate its resources, and its personnel and operational policies. It

(C) IFIP International Federation for Information Processing 2013 
must also acquire engineering capabilities and technologies that enable it to maximize its performance. In this scenario, maintenance actions are part of the production process and can influence the company's position in relation to its competitors as well as to its business strategy. If this is done, maintenance management may be a production activity that adds to profits rather than only an unavoidable business cost [4].

The main objective of maintenance management is to plan the operational system and to manage the product (benefit and/or service). Thus, it is premised on its being deployed to supervise and control the occurrence of failures in a production plant. This task can become complicated and the use of methodologies can facilitate understanding how to analyze the context.

One of the methodologies used for the effective management of failure is preventive maintenance. This methodology specifies maintenance activities to ensure the plant functions for a given period of time, and to avoid production stopping unexpectedly. One of the approaches that adopt this methodology is Reliability Centered Maintenance (RCM).

$\mathrm{RCM}$ is understood as a procedure that is able to identify requirements for preventive maintenance in complex systems in order to preserve or maintain materials, people and equipment on the production line in acceptable conditions [5]. When RCM is combined with other approaches, it provides a complete understanding of the operational context, and provides management and financial information throughout the organization.

From this perspective, the use of information technology resources can offer some advantages to organizations worldwide, since they enable complex data to be managed and operations to be planned [6].

The main contribution of this paper is to put forward a Decision Support System for maintenance management. To this end, it will present the methodologies and framework concepts used to model the system as well as a brief study of the system requirements for the maintenance area.

\section{Reliability Centered Maintenance}

RCM is an approach that considers the economic prioritization and the security function of the production system; thus, its main contribution is to identify opportunities to do preventive maintenance in order to ensure that any physical component continues to fulfill its operational functions [5]. This is why the flow of preventive maintenance activities must be consistently modeled.

In addition, RCM is used to develop and select maintenance alternatives based on the operational, economic and safety criteria of a production system. This method is shown to be a systematic process for managing functional and operational failures [7].

First of all, RCM identifies the appropriate maintenance tasks for maintaining the current reliability level of resources and people in the production environment, which will reduce costs in the maintenance operation [8]. 
Essentially, RCM presents a methodology based on subjective basic questions that may be extended to any applications [9]:

- Is the cause of failure obvious to the operator?

- What is the consequence of failure?

- What tasks can be selected to prevent this failure?

- What is the reason for selecting a specific task?

- What is the suggested scope of the task?

These simple questions enable extensive knowledge about the operational context of organizations to be gained. While the answers are being given, the system is mapped and relevant information about the occurrence of failures is highlighted. This mapping may be presented in the form of a logical diagram in which the steps correspond to those of the RCM.

\subsection{Main Steps of the RCM}

Different sequences for implementing the $\operatorname{RCM}[6,10,11,12]$ are identified, but the main benefit offered by this methodology, is knowledge about the entire maintenance process, which depends on the detail level given in the process [13].

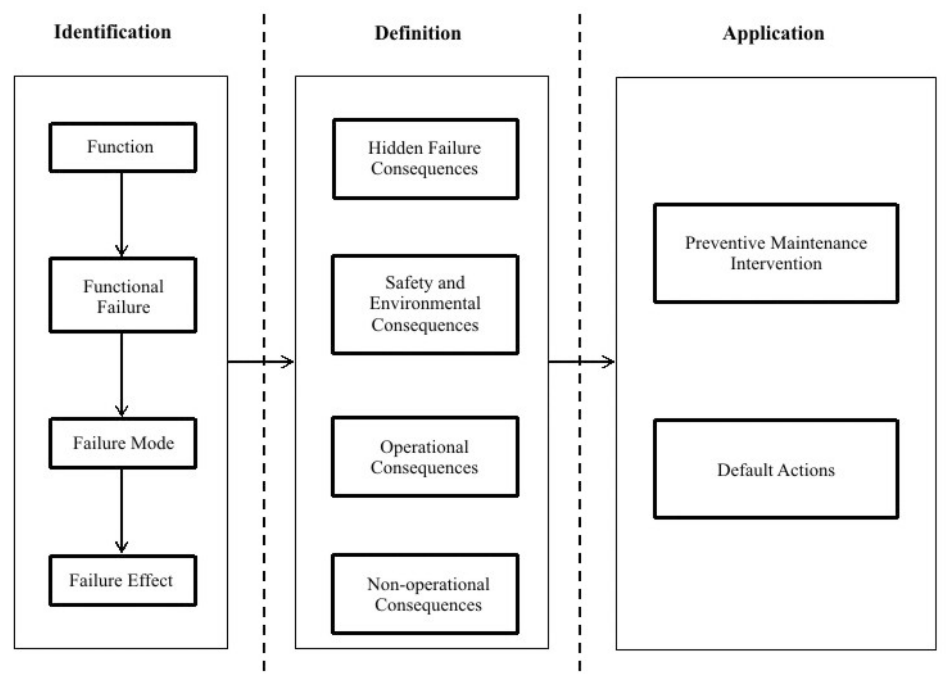

Fig. 1. Simplified representation of the RCM process [17]

In the first instance, the RCM process follows recognizing and identifying the functional requirements of the items in the production context and it establishes the desired reliability levels. For each item, it identifies specified functions and the functional failures associated with them. Then, an analysis is carried out on the failure mode and its effects [14]. This concept is very important for the maintenance context 
because it analyzes the existing risk in the operational production $[15,16]$. Then, the process defines the consequence type observed because of the occurrence of the given failure. These consequences are present in four categories: hidden, safety or environmental, operational, and non-operational [12]. Thus, the process identifies the maintenance actions to be put in place in the production system. In general, two profiles of maintenance actions are applied: preventive maintenance and corrective maintenance. Figure 1 presents the simple process of RCM.

The RCM process offers advantages and opportunities to improve the performance and safety of equipment throughout the production process by minimizing waste and machinery downtime [5]. The effort to maintain a consistent assessment process enables accurate and timely information to be obtained, which are important features for maintenance management [18].

In the maintenance area some data are considered strategic, especially those regarding the failure rate, downtime, time to repair and all historic data related to these variables [19]. These data are obtained in general from the performance records of a corrective maintenance service and from experts' knowledge.

The logical structure of the RCM process presents consistency for the specification of an information system that is able to process and provide information for the maintenance area. In this treatment, the focus is placed on the context of industrial production, and aims to extract information from the strategic level for maintenance actions [20].

Strategic level information is characterized by the non-structured data that are presented and therefore the introduction of a Decision Support System (DSS) is timely. The consideration of requirements to shape the system model is important before introducing a DSS.

\section{Maintenance Management System Requirements}

Using Information Technology resources presents data processing advantages in the business context. Data treatment offers gains in speed and certainty in the decision making process. Thus, the use of information systems adds value to the operational functions of an organization [21].

Adding value in the production context is crucial for acquiring a competitive advantage in the context of current business, since the trend for consumers to require product differentiation is increasing. In light of these arguments, the acquisition of an appropriate information system is essential.

An appropriate information system is one that not only meets the needs of management in the organization as it provides relevant information for decision making but is also an information system that helps the organization achieve its objectives at different levels: operational, tactical and strategic [22].

In general, an information system should meet the development requirements imposed by the user of the service. The user's role is to provide information about his/ her preferences and needs with regard to using the information system. Among the 
requirements are those that refer directly to the characteristics of the information system and the reliability and quality associated with the system.

These groups of requirements are defined by the context in which the information system is inserted. In general, an information system must present values for six crucial aspects [23], which are described in Table 1.

Table 1. Description of the requirements of an information system

\begin{tabular}{|c|c|}
\hline Requirement of Information System & Description \\
\hline System Quality & $\begin{array}{l}\text { The information system should meet the client's } \\
\text { needs satisfactorily }\end{array}$ \\
\hline Information Quality & $\begin{array}{l}\text { The information system should provide relevant } \\
\text { and timely information }\end{array}$ \\
\hline System Use & $\begin{array}{l}\text { The information system should deal with } \\
\text { cognition requirements and usability }\end{array}$ \\
\hline User Satisfaction & $\begin{array}{l}\text { The information system should be easy to } \\
\text { operate and/or keep in operation }\end{array}$ \\
\hline Individual Impacts & $\begin{array}{l}\text { The information system should enable the user } \\
\text { to learn, thus encouraging individual } \\
\text { development }\end{array}$ \\
\hline Organizational Impacts & $\begin{array}{l}\text { The information system should have well- } \\
\text { informed data on operational performance }\end{array}$ \\
\hline
\end{tabular}

For each operation in the organization there is one information system type that is the most appropriate. In the exercise to define maintenance strategies, the appropriate information system is the one that, in addition to providing operational information, supports the decision-making process. A Decision Support System is a type of information system that has specific functions that enable simulations to be conducted and scenarios to be modeled using a structure with a database of the data on thwe requirements/criteria and a database of the model obtained from dialogic interaction with the user [24].

For the context of maintenance management, data processing is essential. It is present at all organizational levels. The demand for maintenance management illustrates different perspectives on implementing an information system. These perspectives take into consideration the goal, purpose, use and user of each organizational level.

At the strategic level, the information system for the maintenance area has the following features: its goal is to ensure the cost-effectiveness of maintenance; its purpose, decision support; its main use is for data output (report generating facility, integrating information technology); and its user is the maintenance manager [21].

The process of identifying the demands on the information system in the maintenance area follows different methodologies. It is important that the steps of the process are outlined so as to meet the real needs of the context.

Implementing a Decision Support System for the maintenance area contributes to structuring the subjectivity of the context. Therefore, the occurrence of failures and 
interruptions to production are registered consistently and this enables the performance of the maintenance to be maximized with regard to preventing or correcting failures. Thus, it comes to be seen as a management tool that adds value.

The use of specific concepts and specific methodologies of the maintenance area assists in processing knowledge and identifying the several factors and elements involved, in context. The RCM process enables interactions of these factors to be identified. Thus, the logical structure of RCM was used to facilitate the modeling of the DSS presented for maintenance management.

\section{A DSS for Maintenance Management}

The main goal of this section is to describe and justify a decision support system for the maintenance area. In this perspective, the RCM process was used to outline the application context and the features of the system as per management needs. Thus, the DSS enables the maintenance actions that best suit the scenarios analyzed to be visualized and identified.

\subsection{System Architecture}

Maintenance actions can be applied to different items belonging to the production system. To this end, what must be known are the several interactions between the components of the system and the equipment in operation. This is a requirement addressed by the DSS proposed, which enables complete knowledge of the production system to be obtained.

To address this consideration, the DSS presents an architecture comprising modules that enable the complete identification of components and their operations in the production system. DSS has two main modules: (i) a physical module and (ii) a functional module. These are described in Table 2

The cognitive aspects considered include the usability of the components and constant access to information. This requirement is critical to the maintenance area, in view of the constant monitoring of changes.

Table 2. Description of the modules of a DSS

\begin{tabular}{lll}
\hline Module & Activity & Data \\
\hline Physical & Registry & $\begin{array}{l}\text { Item of production system } \\
\text { Occurrence of failures } \\
\text { Failure detection levels }\end{array}$ \\
& Registry & $\begin{array}{l}\text { Data on the system, subsystem, } \\
\text { function, functional failure, equipment } \\
\text { and components, failure modes }\end{array}$ \\
& Analysis & Criticality of failure modes \\
& Definition & Maintenance Strategy \\
\hline
\end{tabular}


Both modules provide a complete view of the context studied in the maintenance area and allow a direct flow to the users of the system. However, the Functional Module provides consistent features to define the maintenance strategies desired by organization.

\subsection{Main Flow of the Functional Module}

The main flow of the Functional Module of DSS is to insert user data, to validate data by means of the several interactions and to analyze data and, finally, to provide an analysis the results for decision making.

All functional features of the module correspond to steps developed by the RCM process. Thus, there are occurrences of failures analysis and criticality analysis of failure modes that form the foundation to define strategic actions to maintain the items in the analysis of the production system. The process undergone by the Functional Module may be represented in five steps which are illustrated in Figure 2.

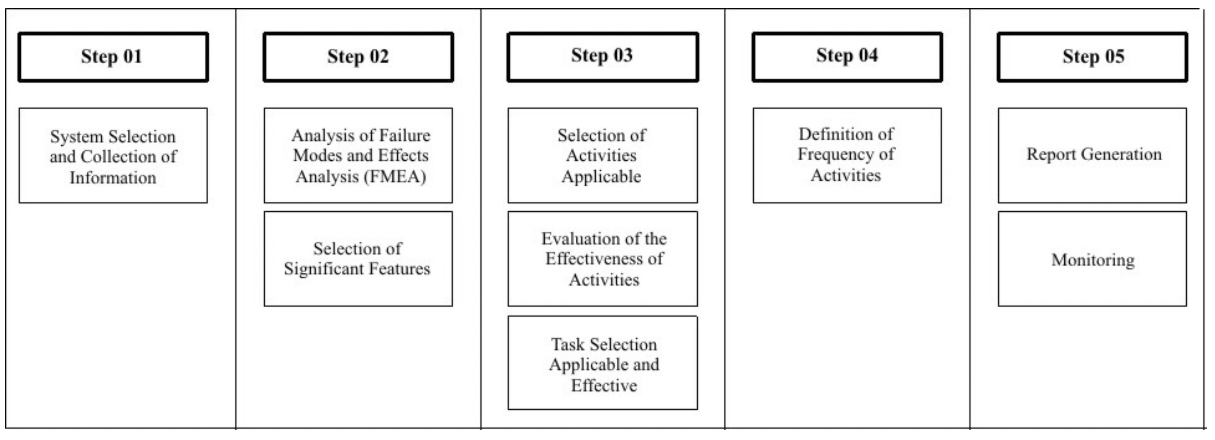

Fig. 2. The structure of the Functional Module consists of five main steps, which are defined by the features of the system

The steps of the Functional Module of DSS enable a sequence designed for a simple navigation in the system to be viewed. It is important that the requirements of the system are obtained so as to construct this sequence. A hierarchy of the functional components was created in order to design a productive context for the DSS.

Thus, consider a productive process. A system is characterized by a set of items that has a higher functionality. This system can consist of subsystems, and those for other subsystems. Each system or subsystem has a function. This function may comprise several potential functional failures that are described by the conditions of operation of the system or subsystem. Each functional failure can occur in an item or a set of items in the production system. For each occurrence of failure on an item there is a failure mode associated with it. This failure mode informs the manner and context that led to the occurrence of a functional failure. Each failure mode presents essential characteristics to determine its criticality as it is important to identify how critical the failure mode for the production system is. 
In DSS this sequence is shown in a hierarchy, which facilitates visualizing and compiling elements in the production context. Figure 3 represents the interface of the functional module of the DSS, with emphasis on the evaluation stage of the critical failure mode.

An analysis of the criticality of the failure mode is a very important resource used to define maintenance actions. This issue is closely related to the levels of risk the organization is willing to face. Many studies have been developed to provide a consistent approach so as to obtain the criticality level of the failure modes $[14,16]$.

In the DSS, the criticality analysis is structured by a mathematical model that classifies the severity and risk associated with a failure mode. The information required for this analysis suggests that the user should set qualifying levels of detectability and frequency of failure, as well as levels of severity in line with o the damage: human, environmental, operational and financial, caused by the occurrence of the failure mode in specific equipment the production line, as illustrated in Figure 3 .

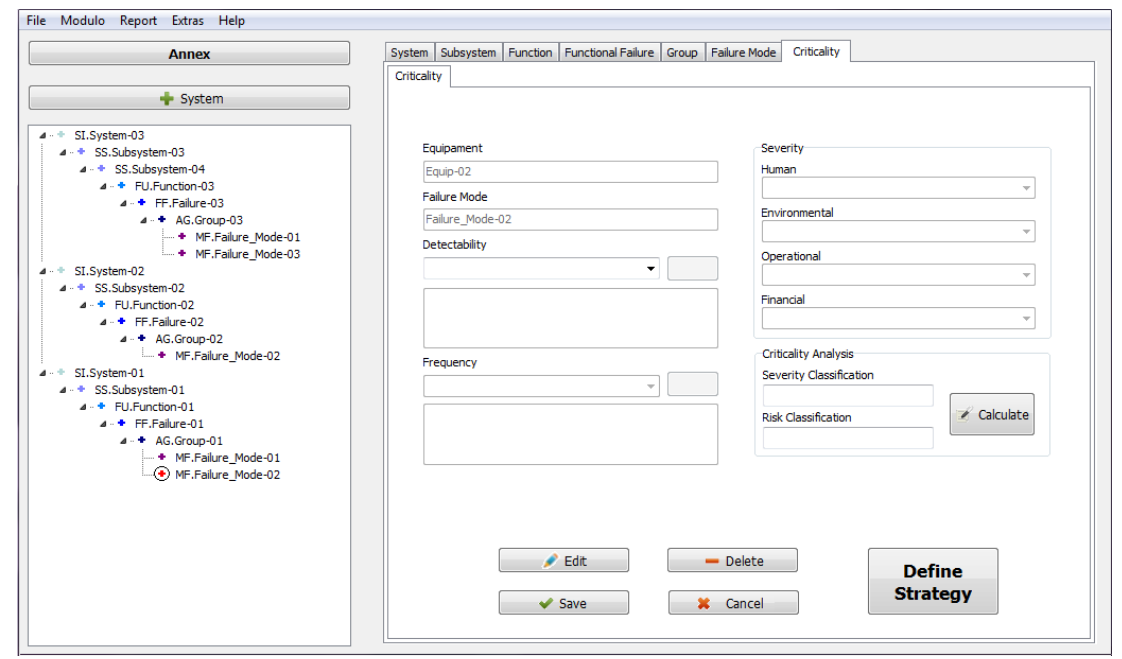

Fig. 3. This is the interface for defining the criticality of failure modes. The hierarchy of the items of the production system is shown on the left. The definition of criticality of failure modes is calculated from the data on detectability, frequency and severity.

After acquiring this information, what follows is to define strategic maintenance actions for the production system, especially for the operations of each piece of equipment/item.

\subsubsection{Definition of Maintenance Actions}

The information extracted from the DSS depends on the frequency of the occurrence of the failure modes of the production system under study. The information 
contributes to a summarized analysis of the occurrence of failure, a critical step in defining strategies for maintenance actions.

Classifying the severity and the risks is the basis for defining the critical failure mode. This definition is based on a correlation matrix that identifies how critical the occurrence of a failure is for the production system. In turn, the criticality encourages the mechanism to define the maintenance action.

The process of defining the maintenance action considers several aspects, including cost, timing of maintenance and operational safety in the production system. Thus, to establish the most appropriate strategy for the context under study, the DSS follows a specific logical diagram which is guided by the RCM methodology.

Based on the basic issues of the RCM process, questions are designed to outline the context, given the objects observed (system, subsystem, function failure, and failure mode group) that were selected. The questions are provided in a logical sequence while the maintenance action recommended by the system is being defined. Figure 4 represents the interface to define the maintenance action.

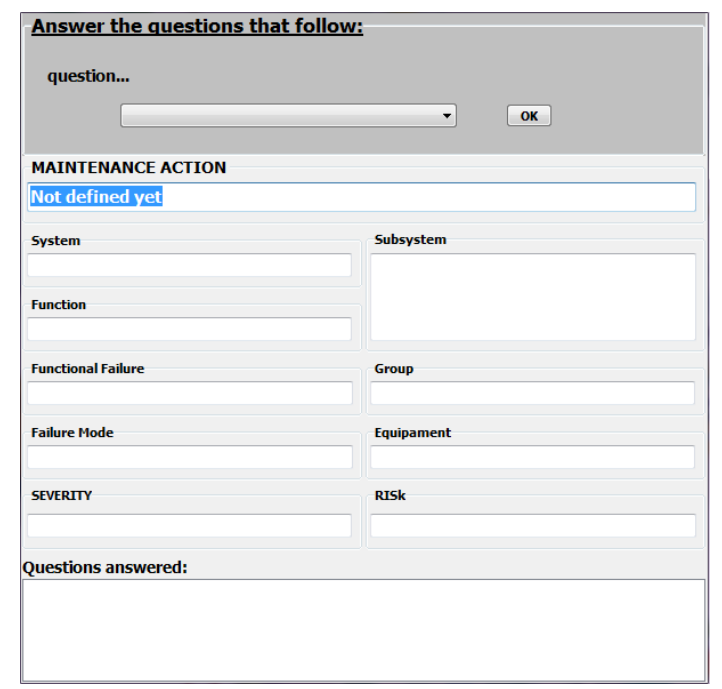

Fig. 4. This is the interface for defining the maintenance strategy. The user must answer the questions by following a sequence diagram. This process will recommend the most appropriate maintenance action for the situation.

It is simple to obtain the process for a maintenance strategy. The questions listed are direct ones and the process enables answers to be categorized. This feature adds value to the process, and aims at the usability of the information system.

Among the alternatives offered by the DSS are: scheduled restoration, scheduled discards, on condition, redesign, failure-finding, not scheduled, combination of tasks and capacity and training of staff. Table 3 gives a description of each maintenance action recommended by the DSS. 
The type of maintenance action recommended will depend on the context analyzed. However, it can be helpful to list the aspects considered relevant to define the strategy process: cost, quality and production performance. From this consideration, it can be concluded that there is a relationship between business strategy and maintenance strategy [25].

Table 3. Description of maintenance strategies recommended by the system

\begin{tabular}{ll}
\hline Strategy Maintenance & Description \\
\hline Scheduled restoration & $\begin{array}{l}\text { Restoration of the initial production capacity of an } \\
\text { item or component }\end{array}$ \\
Discard of an item or component before the age \\
limit specified
\end{tabular}

The benefits of DSS are moreover based on the type of maintenance action recommended. For these actions that enable the time interval to be analyzed, modeling to estimate the maintenance period based on the inspection and maintenance based on replacing pieces of equipment/items are suggested.

This resource is central to the maintenance strategy, since after learning what to do, it is essential to know when to do it. The results of time analysis are based on mathematical modeling of the specific items of the maintenance area and these are illustrated graphically to the user. Thus, the reports of maintenance activities are consistent since all that needs to be considered doing in the same time period is shown.

Another contribution to define maintenance strategies is the use of multicriteria methods to criticality analysis. The use of multicriteria methods is often in maintenance area in special when complex problems are highlighted in maintenance management systems [26,27]. Some examples these problems in maintenance area include risk evaluation [28,29], outsourcing and logistics [30], project management $[31,32]$ and many others.

\section{Conclusion}

Investment in information technology in the maintenance area presents is an important resource to strategic position in the competitive context [26]. Since this 
investment enables value to be added to the decision-making process, it ensures the operational conditions of the organization are satisfactory.

DSS provides a logical sequence for the particular definition of maintenance strategies and provides features that allow a wide understanding of the scenario studied. The application of the DSS satisfies the needs of the maintenance area in the industrial context and is able to deliver results and benefits in any organizational context. Thus, it becomes a tool to support operations management and on which recommends strategic activities.

Thus, this prompts the development of research into the interaction between the concepts involved in the maintenance area with the concepts of decision theory. This article also shows that the multicriteria decision-making process can make a contribution to constructing a new perspective on the occurrence and definition of maintenance actions based on analysis of the criticality failure mode.

\section{References}

1. Campos, A.C.S.M., Daher, S.F.D., Almeida, A.T.: New patents on Business Process Management Information Systems and Decision Support. Recent Patents on Computer Science 4, 91-97 (2011)

2. Dekker, R.: Applications of Maintenance Optimization Models: A Review and Analysis. Reliability Engineering \& System Safety 51, 240-299 (1996)

3. Pintelon, L.M., Gelders, L.F.: Maintenance management decision making. European Journal of Operational Research 58, 301-317 (1992)

4. Verdecho, M.J., Alfaro-Saiz, J.J., Rodriguez-Rodriguez, R.: Prioritization and management of inter-enterprise collaborative performance. Decision Support Systems 53, 142-153 (2012)

5. Moubray, J.: Reliability-centered Maintenance: RCM II. Ind. Press Inc., New York (1997)

6. Deshpande, V., Modak, J.: Application of RCM for safety considerations in a steel plant. Reliability Engineering and System Safety 78, 325-334 (2002)

7. Jones, R.: Risk-based Maintenance: A Reliability-centered approach. Gulf Professional Publishing, Houston (1995)

8. TM 5-698-2.: Reliability-Centered Maintenance (RCM) for Command, Control, Communications, Computer, Intelligence, Surveillance, and Reconnaissance (C4ISR) Facilities. US Department of the Army, Washington (2006)

9. Jia, X., Christer, A.H.: Case Experience Comparing the RCM Approach to Plant Maintenance with a Modeling Approach. In: Blischke, W.R., Murthy, D.N.P. (eds.) Case Studies in Reliability and Maintenance. John Wiley \& Sons, Inc., Hoboken (2003)

10. Rausand, M.: Reliability centered maintenance. Reliability Engineering and System Safety 60, 121-132 (1998)

11. Matteson, T.D.: Airline experience with RCM. Nucl. Engng. Design 89, 385-390 (1985)

12. Nowlan, F.S., Heap, H.: Reliability-centred maintenance. National Technical Information Service, US Department of Commerce, Springfield, VA (1978)

13. Smith, A.M., Hinchcliffe, G.R.: RCM: Gateway to World Class Maintenance. Elsevier Butterworth-Heinemann, Burlington (2004)

14. Alencar, M. H., Almeida-Filho, A. T., Almeida, A. T.: An MCDM model for potential failure causes ranking from FMECA. In: Esrel 2012/PSAM 2011, Helsinki (2012) 
15. Braglia, M.: MAFMA: multi-attribute failure mode analysis. Journal of Quality \& Reliability Management 17, 1017-1033 (2000)

16. Dong, C.: Failure mode and effects analysis based on fuzzy utility cost estimation. International Journal of Quality \& Reliability Management 24, 958-971 (2007)

17. Hipkin, I.B., Lockett, A.G.: A Study of Maintenance Technology Implementation. Omega 23, 79-88 (1995)

18. Abdul-Nour, G., et al.: A reliability based maintenance policy: a case study. Comput. Ind. Eng. 35, 591-594 (1998)

19. Christer, A.H., Whitelaw, J.: An Operation Research Approach to Breakdown Maintenance: Problem Recognition. The Journal of Operational Research Society 34, 1041-1052 (1983)

20. Kans, M.: An approach for determining the requirements of computerised maintenance management systems. Computers in Industry 59, 32-40 (2008)

21. Melville, N., Kraemer, K.L., Gurbaxani, V.: Information technology and organizational performance: an integrative model of IT business value. MIS Quarterly 28, 283-322 (2004)

22. Delone, W.H., Mclean, E.R.: Information systems success: the quest for the dependent variable. Information Systems Research 3, 60-96 (1992)

23. Powell, R.L., Dent-Micallef, A.: Information technology as competitive advantage: the role of human, business, and technology resources. Strategic Management Journal 18, 375-405 (1997)

24. Watson, I.: Case-based reasoning is a methodology, not a technology. Knowl.-Based Syst. 12, 303-308 (1999)

25. Pinjala, S.K., Pintelon, L., Vereecke, A.: An empirical investigation on the relationship between business and maintenance strategies. International Journal of Production Economics 104, 214-229 (2006)

26. Almeida, A.T.: Multicriteria decision making on maintenance: spares and contracts planning. European Journal of Operational Research 129(2), 235-241 (2001)

27. Cavalcante, C.A.V., Ferreira, R.J.P., Almeida, A.T.: A preventive maintenance decision model based on multicriteria method PROMETHEE II integrated with Bayesian approach. IMA Journal of Management Mathematics 21, 333-348 (2010)

28. Brito, A.J., Almeida-Filho, A.T., Almeida, A.T.: Multi-criteria decision model for selecting repair contracts by applying utility theory and variable interdependent parameters. IMA Journal of Management Mathematics 21, 349-361 (2010)

29. Brito, A., Almeida, A.T.: Multi-attribute risk assessment for risk ranking of natural gas pipelines. Reliability Engineering \& Systems Safety 94, 187-198 (2009)

30. Almeida, A.T.: Multicriteria modeling of repair contract based on utility and Electre I method with dependability and service quality criteria. Annals of Operations Research 138, 113-126 (2005)

31. Alencar, M.H., Almeida, A.T.: Assigning priorities to actions in a pipeline transporting hydrogen based on a multicriteria decision model. International Journal of Hydrogen Energy 35, 3610-3619 (2010)

32. Mota, C.M.M., Almeida, A.T.: A multicriteria decision model for assigning priority classes to activities in project management. Annals of Operations Research (Online) (2011) 